\title{
IT media for the development of technical education in Iraq
}

\author{
Hassan B. Hashim* \\ Middle Technical University, Baghdad, Iraq
}

\section{(C2017 ACCENTS}

\begin{abstract}
The main objective of research is to discuss working methods and conduct to statement clue and announcement technologies in education and technical institutions the professional and special ways of set of beliefs and way of life and sharing through the internet and the utilization of the default locations and electronic libraries. This examination will give a down to earth discernment to the trading of skill and sharing of instructive assets and the joint utilization of assets over the bank is set on the internet and is provided and misused mutually by instructive foundations and specialized with the organizations that consent to the foundation of the association. The advancement of instruction and innovation in the time of learning and data requires to change and improvement of the ways and showing strategies and preparing to agree to the imperative of advancement of data innovation and correspondences. Since this improvement open to the field of instruction and preparing up to new skylines as far as accessible means and conceivable outcomes and new advancements utilized and created in present day instructive substance, however then again, the privilege of misuse of this improvement puts training field before a considerable lot of the difficulties and stakes: the amount and quality and economy and methodology. It is quantitatively related to confront the growing quantities of understudies and trainees, but qualitatively is represented mainly at winning the bet on quality; it demands now formation programs of high quality, which ensure efficient configuration and high efficiencies. That economic bet is to provide equipment, resources necessary computers, media networks and technical equipment. For the new strategy, what necessitates and development of plans and mechanisms are needed to develop programs and formation necessary for human resources.
\end{abstract}

\section{Keywords}

Information technology, Technical and vocational education.

\section{Introduction}

The fundamental purposes behind the snags to the advancement of specialized and professional training in Iraq are a small number of types of instruction for industrial schools that allow the combination of work and study and the absence of instructive projects that prepare graduates to enter the small business and help them to set up their own productive projects called intellectual leadership programs. Another vital disservice is that the cost of instruction, which is typically contrasted and the high cost of state funded training due to the idea of the workshops, logical and common-sense hardware, gear and general gear. The Second International Conference on Technical and Vocational Education, held in Seoul in 1999, underlined the requirement for innovation and specialized and professional instruction frameworks to adjust to the improvements of globalization and present-day data and correspondence advances, making information based society in fascinating methods for Instruction and new preparing.

*Author for correspondence
With a specific end goal to combine the confidence in the significance of professional and specialized training and the coveted part in the light of these advancements and changes, these progressions must guarantee brilliance, importance, adaptability, intensity and productivity. From the specificity, destinations and necessities of specialized instruction, we depict various thoughts that can add to the advancement of specialized training projects to empower them to accomplish their objectives and goals successfully, including the requirement for expanded participation and constant coordination between instructive foundations And the work showcase. The expanding familiarity with the way that present day data innovation is vital and essential to build the adequacy of specialized and professional instruction frameworks and make them more sensible and adaptable, and additionally the nonstop advancement of educational program to meet the changing needs of the work advertise in the light of logical and mechanical improvement on the planet; Attention to summer preparing honed by understudies in gainful organizations amid the time of study and summer excursion and coordination with 
these foundations in such manner, and work to make a sort of reliance and mix amongst programming and learning, and concentrate on the preparation and recovery of the specialized preparing and the quantity of specialized coaches, raising the level of logical and instructive and reach the discharges of current improvement, with the significance of concentrating on the down to earth side of the application is more critical from the hypothetical side, and to embrace the preparation and the instructing of compelling projects in light of present day data and correspondence innovation, and work on Promote correspondence and utilization of aptitudes, and thus the need to receive instructive approaches that incorporate more flat and vertical coordination and mix $[1,2]$.

\section{Problem statement}

The importance of technical schools in dealing with labor market issues and their role in achieving logical and innovative progress is the main source of qualified work that society needs. The importance of specialized and vocational training in its impact on social and economic fields, cultural and future development, and the general education strategy of the country. In the current circumstances of Iraq, where infrastructure has been destroyed, it has adversely affected the improvement of specialized and vocational education and has led to a shortage of talented and qualified workers. Here is the search for answers to the accompanying query: What is the important part of information technology leading to the advancement of technical and vocational education?

\section{Research importance}

The importance of this research lies in the importance of the use of data in the promotion of specialized and vocational training, which adds to the change and modernization of universities and specialized institutions and emphasizes the importance of this type of education as a social and social need and keep abreast of time developments. For specialized vocational education to play its role in achieving development plans, an effective and flexible ICT education system must be established in its methodology, relevant to labor market requirements, accessible to all and capable of fulfilling its obligations to society. The aim of the research is to identify part of the technological innovations in improving professional vocational education and to try common logical research to help learners in the field of training with the speed of providing data to them.

\section{Research objectives}

The objectives of this paper are to identify the requirements for the development of technical and vocational education and to benefit from scientific research in the field of distance education in order to cope with the rapid and continuous development of ICTs:

1. Identification of potential information resources to support technical education.

2. To improve and develop skills using e-learning.

3. To evaluate the performance of the e-learning system.

\section{Search limits}

Is to depend on past sources and writing that managed ebb and flow examine factors:

1. Information for the most part of the expertise. Idea of innovation has been associated with the exact use of legitimate learning or information sorted out for logical purposes. It can be presumed that data innovation is an orderly strategy that takes after sorted out information and uses all physical or immaterial assets in a powerful way to achieve wanted work to an abnormal state of flawlessness.

2. Technical professional this arrangement, which incorporates instructive readiness and behavioral direction, and the procurement of the expert aptitudes and capacities of customary establishments.

\section{Literature review}

In [3] the e-learning team (ESSTT) presented works related to pedagogy and research, in particular to evaluate the pioneering e-learning experience and the experience was very promising, especially language learning courses. In the second part of this paper, the researcher presented research work related to the intelligent e-learning system. This is based on the combination of two known approaches (LSA) and (AWL), they have developed a prototype.

The aim is to contribute making e-learning accessible to students with disabilities and special needs, by developing a virtual curriculum on basic computer and Internet training in educational education [4]. The aim of this research work is to increase access to e-learning environments for the disabled [4].

Rezaei [5] provided a reasonably comprehensive summary of the main current areas of the necessary interaction between the worlds of e-learning and the digital library. Digital library services are an essential element of a high-quality e-learning system. Parts of 
the world cannot be physically accessed by large academic and research libraries. Those who use, learn and evaluate these resources require constant technical, reference and educational support, libraries to redefine their values and services, and to collaborate with their users.

Shanks [6] investigated and demonstrated the significance of this kind of education, the conscious understanding of technology and dealing with it and developing it and work to meet the requirements of work and acquire general and specialized skills, the requirement for the work showcase is straightforwardly identified with current and planned development needs.

Baloh et al. [7] tackled the impact of the Internet and information technology on human resources work and management. He also referred to the main developments and (inevitably coming) changes in the areas of employment, motivation, leadership and discussion of possible adjustments to regulation and business. To detect global changes and consequences in Slovenia and to identify promising future trends.

\section{Hypothetical framework (Theoretical framework)}

\subsection{Technical and computer education}

The start of computer use in education dates back to the 1960s when technology was invented and developed for this new tool (PC). Computer aided learning (CAL), and in addition computer assisted instruction (CAI), has flourished and developed over the years thanks to significant advances in software and media equipment also, specialized gadgets to become educational audio-visual devices used to teach students and training courses and provide them with various skills [8].

\subsection{Computer-assisted learning methods}

(A)Method of direction the goal of this method is to control the learner to achieve education by presenting the concepts and fundamentals of educational materials with the addition of necessary information in essential parts of the material notes. (B) Practice and training this method depends on the computer as an assistant in traditional education through programs that are placed on its computer, suggested practices in a variety of skills and teaches the learner to solve issues through repetition training. (C) Simulation method the simulation mode is intended to encourage the learner's portrayal of a particular phenomenon, idea, process or particular situation, the reason for which is inspiration and preparing to settle on their own choices to arrive at an explanatory hypothesis to solve the problem. Learning in this way is a means of discovery, as the learner continues to move from one point to another through notes that understand and connect them to come to a final outcome to pick the privilege decision. (D) Method of computer as a special teacher In this case, the computer is the place of the teacher, but individually, the computer knows one pupil or that the student learns on its own. The work is in this case to clarify the idea of what the computer is prepared in advance and in each step raises a question for the computer and awaits the student's response to this question and then determines the next stage on the premise of the student's response to these questions. And design this kind of programs for many levels and the student can review the lesson several times and the pace of learning in the student according to the level and progress achieved. (E) Method of testing The aim of this method is to distinguish the extent of acquiring and learning cognitive skills for a given subject, contributing to the achievement of student testing and learning assessment and attention ought to be noted because it is more important than the learning process, and must be the items that give to the recognizable proof of educational goals.

\subsection{Internet and distance education}

This mode depends on learning and learning in a private or virtual way, and uses the most modern innovative devices, for example, PCs, software, media and multiple communication networks. Online learning media is the most recent type of separation learning, and the latter rely initially on correspondence by mail and send printed lessons on paper before they develop later and are used as laser discs [9]. The development now is the result of two main factors: Digital Progress Especially it is possible to integrate a variety of content such as text, video, audio and video, which was required by different media and companies and this factor is socalled multimedia. The second factor is the great development that has occurred in the world of communications and networks, especially the Internet.

\subsection{Advantages of distance learning via the Internet}

(1)Overcome distance barriers as an individual can learn from his position; (2) It is anything but difficult to contact teachers, colleagues and digital virtual libraries; (3) Eliminate the teaching of the syllabus, which depends on the process of indoctrination. Keeping in mind the end goal to give the learner a 
key role; (4) Participates in the self-learning process because it prefers interactive lessons ; (5)Enhance the nature of substance and utilizing interactive media innovations for computerized innovation; (6) Calm the weight on the foundation of establishments committed to instruction and preparing, development expenses and workshops; (7) Refreshing the national framework and enhancing the reaction to the genuine needs of the work showcase, where the instructive organization keeping in mind the end goal to recognize educators of educational module and preparing to be received by vital targets; (8)To develop positive attitudes for students' professional and specialized education, and to change the perceived inferiority of society towards this education and improve its popularity.

\subsection{Online distance learning requirements}

Set up the necessary infrastructure of networks and computers to provide remote education, demo, management and remote operation for all users. The administrative side of the preparation and organization of materials from the private and public sector, how to calculate and work teachers, and the enactment of laws and standards for evaluation.

\subsection{Planning for distance learning courses}

Focus here is a critical process for formulating a lesson plan prepared for distance learning. This process requires proportioning to new features of virtual learning. Even the quality assurance required must be available in the lesson. These are a portion of the characteristics of this sort of adapting, for example, interpretation of information, full integration, good selection of lesson components and the most appropriate way to formulate content, picture, sound and video clips [10]. The restructuring of the lesson and a good division of pages along with the thrill and excitement and motivate the learner to move and progress in the lesson and to ensure the involvement and development of the dialectical dimension in the educational process regarding the self-pattern to accommodate. There are two approaches to prepare lessons: (1) The first is to get ready-made lessons that have been written on the Internet and can be immediately exploited and taught to students, and it is known that the United States is completely in control of this market - the substance of the study - the market industry where we find that there Many of the suppliers specialize in these fields, for example, $\mathrm{P}$ lessons, communications, mathematics, physics, business science, economics, etc. One of its main positives is the high quality these lessons contain, both at the level of programming formulation or the level of scientific content value. The principle boundaries to high cost, where these suppliers usually control these lessons by controlling the copyright requirements and this led to the exploitation of education or training, so the organization is required to get a (license) contributions to each student to pay large amounts annually: (2) And the second method consists of lessons developed under the same instruction and preparing organization $[11,12]$.

\subsection{Importance of (virtual library) in the distance learning process}

A virtual library is a library that captures the sources of digital information, whether produced in digital form or changed over into advanced format. Its operations are controlled by the automated system and accessed through a system of interconnected PCs, Local, or through the global Internet. What we are experiencing today from the communications revolution and the advancement of the Internet has prompted the rise of virtual libraries that rely on collecting information from global libraries around the world through the World Wide Web and the networks of cooperation associated with each other. 8. Use programs to prepare instructors and understudies: One of the most common mistakes in many private, government and educational institutions is the absence of a focus factor on training. There are a ton of points that can be invested in creating an integrated system for online distance learning, searching for all programs and physical aspects, and not ignoring training, which in turn leads to failure or failure to benefit from the system as required. Therefore, we accentuate the significance of training for each student and the start of every semester of preparing on the most proficient method to utilize the framework and in addition for teachers so that training continues on this basis or when needed.

7.8 Use programs to train teachers and students One of the most common mistakes in many private, government and educational institutions is the absence of a focus factor on training. There are a lot of points that can be invested in creating an integrated system for online distance learning, searching for all programs and physical aspects, and not ignoring training, which in turn leads to failure or failure to benefit from the system as required. Therefore, we emphasize the importance of training for each student and the beginning of each semester of training on how to use the system as well as for 
teachers so that training continues on this basis or when needed [13].

\section{Research methodology}

The examination outline strategy utilized for a gathering of expressive and exploratory research included. The poll things were created on the premise of writing and past targets. The poll was reconsidered with the help of exceedingly experienced specialists to contemplate the legitimacy of the exploration display. The survey comprised chiefly of inquiries identifying with the respondents' supposition on different parts of ICT utilized as a part of their establishments. A pre-trial of dependability was directed with a select number of haphazardly chose speakers from five TVET organizations in Iraq. The method of work included a review of the experimental tests on the results conducted at the center for Development of Staff of the Central Technical University in Baghdad to demonstrate the importance of the use of information technology in vocational schools in Iraq.

Aggregate encounters have fortified and bolstered the consequences of the test report in four urban communities in Iraq. A sum of twelve professional schools, where educators and understudies were instructed and prepared on the most proficient method to get to computerized mixed media content. An aggregate of twelve preliminary professional schools took an interest in the examination (Table 1). Four urban areas and four preparing and training schools were chosen. Planned specimens were taken to choose schools for consider. This is because of the nearness of different projects in a few urban communities and in a few schools that utilization PCs to try different things with computerized content in different urban areas and the straightforward arbitrary inspecting used to acquire schools. This guarantees the example speaks to a genuine portrayal of professional schools Country.

Table 1 Cities and schools involved

\begin{tabular}{ll}
\hline Cities & Number of schools \\
\hline Baghdad & 5 \\
Diyala & 2 \\
Waist & 2 \\
Babylon & 3 \\
Total & 12 \\
\hline
\end{tabular}

The exploration utilized three apparatuses, for information gathering a concentration amass discourse for students, a poll for instructors, and a timetable for checking. Singular encounters of creators incorporated the instructing of functional aptitudes, bits of knowledge and proposals for enhancing instructive educational program.

\subsection{Pre-programming analysis}

The work has been classified into the following stages: programming; planning and experimentation. A total of 12 secondary school (vocational) teachers from all cities participated in a five-day workshop to identify and document the required content. Each subject's specialist considered the curriculum.

This step involving teachers in this way is the main consideration in the emergence of digital content. Each subject-based script was then analyzed to determine the modality to be used to capture the corresponding multimedia data.

\subsection{Determining the content of cultural media}

To determine the cultural content appropriate to culture in the planning phase of the work for two variables only, for detailed information on the content of multimedia pages, it was necessary to determine in advance what constitutes cultural significance and understanding the behavior of respondents to learning Table 2 .

Table 2 Trompenaars model of culture differences

\begin{tabular}{|c|c|}
\hline Universalism & Particularism \\
\hline $\begin{array}{l}\text { Universalist societies try to } \\
\text { discover wide and general } \\
\text { standards. At the point } \\
\text { when no standards fit, they } \\
\text { locate the best manage to } \\
\text { comply with. }\end{array}$ & $\begin{array}{l}\text { Particularistic societies } \\
\text { discover special cases, At } \\
\text { the point when no } \\
\text { principles fit, they judge } \\
\text { each case without anyone } \\
\text { else justify, instead of } \\
\text { endeavouring. } \\
\text { constrain fit a current } \\
\text { standards. }\end{array}$ \\
\hline Individualism & Communitarianism \\
\hline $\begin{array}{l}\text { Individualistic societies are } \\
\text { worried about the privileges } \\
\text { of the person; They try to } \\
\text { give every individual a } \\
\text { chance to develop or bomb } \\
\text { alone, and see aggregate } \\
\text { concentration as denying } \\
\text { the person of their rights. }\end{array}$ & $\begin{array}{l}\text { Communitarian societies } \\
\text { look to the privileges of } \\
\text { the general public, They } \\
\text { put the family, gathering, } \\
\text { organization and nation } \\
\text { before the individual, } \\
\text { They consider } \\
\text { individualists to be self- } \\
\text { serving and myopic. }\end{array}$ \\
\hline
\end{tabular}

8.3 Cultural relevance of multimedia content Shows the results, of the differences in cultural relevance of the multimedia content by cities Table 3 . 
Table 3 Results differences cultural

\begin{tabular}{llcll}
\hline $\begin{array}{l}\text { Cultural } \\
\text { Dimension }\end{array}$ & Baghdad & Diyala & Waist & Babylon \\
\hline $\begin{array}{l}\text { Universalism } \\
\text { Individualism }\end{array}$ & high & medium & low & low \\
\hline
\end{tabular}

It has been found that there is a lack of appropriate digital content in technical education schools. The methods of adapting digital content have been classified as shown in Table 4 below. Many of the elearning products that were circulated in schools were simply translated or tailored to meet the needs of the learner and the teacher. This information is the result of data collected through monitoring the quality of digital educational resources in Iraqi governmentsupported public schools. Only the digital content collected for local use and not the foreign content that was approved for use was considered.

Table 4 Multimedia adaptation methods

\begin{tabular}{|c|c|c|}
\hline \multirow{3}{*}{$\begin{array}{l}\text { Content } \\
\text { Teaching and Learning Objective of Digital } \\
\text { Content. }\end{array}$} & Method 1 & \multirow{2}{*}{$\begin{array}{l}\text { Method } 2 \\
\text { Complex knowledge }\end{array}$} \\
\hline & Simple knowledge & \\
\hline & & Hard Skills \\
\hline \multirow[t]{3}{*}{ End User Response to Digital Content } & Reading & $\begin{array}{l}\text { Some Soft Skills } \\
\text { Reading and writing }\end{array}$ \\
\hline & Writing & Listening and Watching \\
\hline & & Interacting \\
\hline \multirow[t]{2}{*}{ Approach to Authoring Digital Content } & $\begin{array}{l}100 \% \text { of content is } \\
\text { translated. }\end{array}$ & $\begin{array}{l}\text { Over } 50 \% \text { constitutes } \\
\text { customized user Specific content }\end{array}$ \\
\hline & & $\begin{array}{l}\text { About } 40 \% \text { constitutes modular context } \\
\text { specific content. } \\
\text { under } 10 \% \text { constitutes originated, culture } \\
\text { specific content }\end{array}$ \\
\hline
\end{tabular}

Schools that cannot be evasive have chosen useful material materials that have been converted into numerical numbers using an adjustment display. With structured content as expressed under method 2, it was discovered that about $10 \%$ constituted a special material for learners, about $40 \%$ put a certain substance, and about $50 \%$ constituted a particular material culture. Units were usually independent, versatile and reusable.

\subsection{Learners response to each multimedia data type}

Table 5 demonstrates the aftereffects of students' reactions to the sort of media information. Clearly, the segments he delighted in most were photographs and recordings. The sound and content components that pulled in less consideration. This is because of the absence of capability of students in English - the dialects utilized as a part of the substance. This implies they were restricted to visual media from interchanges, for example, recordings and photographs. Content protection demonstrates that there are examples of content being too extensive having a little text dimension. This may not be appealing to student Figure 1.
Table 5 Results responses to the Type of multimedia data

\begin{tabular}{llllll}
\hline $\begin{array}{l}\text { Digital } \\
\text { content } \\
\text { data type }\end{array}$ & Baghdad & Diyala & Waist & Babylon & Total \\
\hline Photos & 32 & 18 & 21 & 24 & 102 \\
Videos & 51 & 32 & 29 & 31 & 136 \\
Text & 3 & 2 & 1 & 4 & 10 \\
Audio & 4 & 3 & 6 & 2 & 15 \\
\hline
\end{tabular}

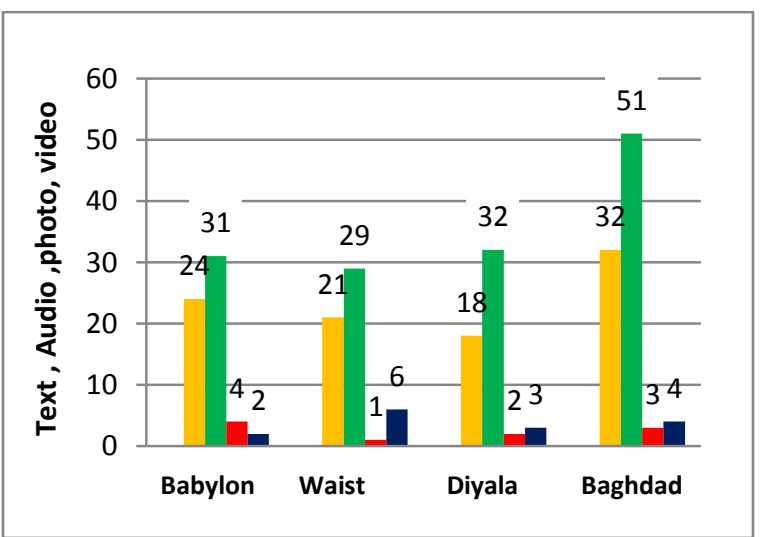

Figure 1 Results responses multimedia data $\&$ cities 
By analyzing Figure 1 (cities, media and Responses) students are shown to tend to the video media in the first place, as shown in the green color of the scheme and according to the cities mentioned, the second place for the photos medium in yellow, the third for the blue sound medium, and images with audio modes, the red color writing texts where students tend to first watch, listen and write a second. The means of video and visual education attract attention and make learners more interactive and participatory and analyse the results very quickly between them.

In spite of these difficulties, it ought to be noticed that students have indicated incredible eagerness in utilizing portable PCs and experiencing content. This movement produced a lot of energy, premium and interest among students and educators even in different classes. He additionally drove the students to examine viewpoints that they didn't care for in the substance that the content and sound are the most male, more research was done to decide why these segments were not appreciated, and it gave the idea that as indicated by students the content was to some degree little and the sound was low now and again.

\section{Conclusions}

In this research, accentuation has been set on the significance of re-establishing instructing, learning and showing techniques utilizing ICTs with the end goal of creating specialized and professional training establishments, and also focusing on distance learning methods through the presentation of its methods, patterns and technical and material advantages, while finding ways and human options to address Lessons to view distance learning online. The improvement and advancement of specialized and professional preparing and the misuse of the accessibility of present day ICT framework can exploit this advancement in the field of professional specialized instruction. Henceforth, we can construct a model for this kind of separation learning through the internet.

\section{Recommendations}

Finding new approaches to utilize ICTs in developing specialized and professional schools curricula. To give specialized and professional training schools with modern equipment, technologies and advanced software to keep up with the scientific development of the developed countries.

\section{Proposals}

The present research suggests that the following studies should be carried out: similar research from the Perspective of experts and IT specialists working in relevant state institutions with specialized and professional instruction researchers.

\section{Acknowledgment}

None.

\section{Conflicts of interest}

The author has no conflicts of interest to declare.

\section{References}

[1] International centre for technical and vocational education and training Bonn. UNESCO-UNEVOC book series: technical and vocational education and training; issues, concerns and prospects. Springer; 2007.

[2] Songa FT. Information technology as a strategy in enhancing competency based education training TVET institutions. Held in Entebbe, Uganda from 7th to 12th 2014 at Imperial Resort Beach Hotel-Entebbe. 2015:165.

[3] Chorfi H, Jemni M. Evaluation and perspectives of an innovative Tunisian e-learning experimentation. In international conference advances in infrastructure for e-business, e-education, e-science and e-medicine on the Internet, l'Aquila 2002.

[4] Jemni M, Laabidi M. The Second African UNESCOUNEVOC TVET Summit E-learning Africa 2008.

[5] Rezaei Sharifabadi S. How digital libraries can support e-learning. The Electronic Library. 2006; 24(3):389-401.

[6] Shanks K. Education and ethno-politics: defending identity in Iraq. Routledge; 2015.

[7] Baloh P, Trkman P. Influence of internet and information technology on work and human resource management. Informing Science. 2003; 6:497-9.

[8] Hammond A. Popular culture in the Arab world: arts, politics, and the media. American University in Cairo Press; 2007.

[9] Chebli H, Jemni M. The virtual University of Tunis, realisations and perspectives. In the third international internet education conference in Cairo, Egypt 2004.

[10] Saud MS, Shuaibu B, Mohrsquo L, Buntat Y, Yarsquo A. Applicability of information and communication technologies (ICTs) in the administration of technical and vocational education and training (TVET) in a knowledge-based society. International Journal of Physical Sciences. 2011; 6(28):6513-20.

[11] El Gamal S, Abd El Aziz R. Improving higher education in Egypt through e-learning programs: HE students and senior academics perspective. International Journal of Innovation in Education. 2012; 1(4):335-61.

[12] Sarkar S. The role of information and communication technology (ICT) in higher education for the $21 \mathrm{st}$ century. Science. 2012; 1(1):30-41.

[13] Russell M, Bebell D, O'Dwyer L, O'Connor K. Examining teacher technology use: Implications for preservice and inservice teacher preparation. Journal of Teacher Education. 2003; 54(4):297-310. 